\title{
Pengaruh Penambahan Sudu Pengarah Pada Kincir Angin Sumbu Vertikal Kelengkungan $90^{\circ}$
}

\author{
Peri Pitriadi ${ }^{*}$, Asnawir ${ }^{2}$ \\ 1,2 Jurusan Teknik Mesin, Politeknik Negeri Ujung Pandang, Makassar 90245, Indonesia \\ *peri_pitriadi@poliupg.ac.id
}

\begin{abstract}
One of the efforts to improve the performance of vertical axis windmills, especially in rotation, is to modify or develop the installation of guide blades. By installing the guide blade, it is hoped that it can reduce the negative torque generated and direct the wind to the concave blade of the wheel. The formulation of the problem to be resolved in this study is how to determine the characteristics of the windmill's rotation with a vertical axis of $90^{\circ}$ curvature in the presence of directional blades. Testing the characteristics of windmill rotation is carried out experimentally, namely by observing or measuring the specified variables to determine the rotation characteristics of the vertical axis windmill type $90^{\circ}$ blade with a directional blade. Observations were made at different wind speeds with variations in the position of the guide blade. The variation in question is the opening position from $0^{\circ}$ to $50^{\circ}$ at wind speeds of $3.2 \mathrm{~m} / \mathrm{s}$ to $4.2 \mathrm{~m} / \mathrm{s}$. The results of the study for different wind speeds, it was found that at the wind speed of $4.2 \mathrm{~m} / \mathrm{s}$ at the opening of the guide blade $50^{\circ}$ the highest rotation value of the shaft was 96.2 rpm and for the lowest wind speed of $3.2 \mathrm{~m} / \mathrm{s}$ at the opening of the guide blade $50^{\circ}$. the lowest value of the wheel shaft rotation is $63.3 \mathrm{rpm}$. So the effect of the guide blade that is installed is that the greater the opening of the blade is given, the greater the rotation of the wheel shaft. Also, the greater the wind speed given the resulting windmill rotation will be greater.
\end{abstract}

Keywords: Windmill, Vertical Axis, Guide blades

\begin{abstract}
Abstrak: Salah satu upaya untuk meningkatkan kinerja kincir angin sumbu vertikal khususnya di putaran adalah dengan melakukan modifikasi atau pengembangan berupa pemasangan sudu pengarah. Dengan pemasangan sudu pengarah diharapkan dapat mengurangi torsi negatif yang dihasilkan dan mengarahkan angin ke sudu cekung kincir. Rumusan masalah yang akan di selesaiakn dalam penelitian ini adalah bagaimana mengetahui karakteristik putaran kincir angin sumbu vertikal kelengkungan $90^{\circ}$ dengan dengan adanya penembahan sudu pengarah. Pengujian karakteristik putaran kincir angin dilakukan secara eksperimen, yaitu dengan melakukan pengamatan atau pengukuran terhadap variabel yang ditentukan untuk mengetahui karakteristik putaran kincir angin sumbu vertikal tipe sudu $90^{\circ}$ dengan sudu pengarah. Pengamatan dilakukan pada kecepatan angin yang berbeda dengan variasi posisi sudu pengarah. Variasi yang dimaksud adalah posisi pembukaan dari $0^{\circ}$ sampai $50^{\circ}$ pada kecepatan angin 3,2 m/s sampai 4,2 m/s. Hasil penelitian untuk kecepatan angin yang berbeda, diperoleh bahwa pada kecepatan angin $4,2 \mathrm{~m} / \mathrm{s}$ pada pembukaan sudu pengarah $50^{\circ}$ nilai putaran poros tertinggi $96,2 \mathrm{rpm}$ dan untuk kecepatan angin terendah $3,2 \mathrm{~m} / \mathrm{s}$ pada pembukaan sudu pengarah $50^{\circ}$ diperoleh nilai putaran poros kincir terendah 63,3 rpm. Jadi pengaruh dari sudu pengarah yang dipasang adalah semakin besar pembukaan sudu yang diberikan maka putaran poros kincir juga akan semakin besar. Selain itu semakin besar kecepatan angin yang diberikan putaran kincir yang dihasilkan juga akan semakin besar.
\end{abstract}

Kata kunci : Kincir Angin, Sumbu Vertikal , Sudu Pengarah

\section{PENDAHULUAN}

Salah satu sumber energi terbarukan adalah energi angin. Energi angin merupakan salah satu sumber daya yang berlimpah, ramah lingkungan dan bersifat renewable, untuk itu sangat berpotensi untuk dikembangkan [6]. Energi yang dapat dimanfaatkan dari angin adalah energi kinetik yang diubah menjadi energi mekanik atau gerak. Dalam pemanfaatan angin sebagai sumber energi terutama sebagai energi gerak, dibutuhkan alat yang berfungsi sebagai penangkap energi dari angin yang 
dikenal sebagai kincir angin [5]. Potensi energi angin di Indonesia yaitu rata-rata kecepatan angin berkisar antara 3-6 m/s. Oleh karena itu diperlukan sistem konversi energi angin yang sesuai dengan profil kecepatan angin di Indonesia [2].

Untuk memanfaatkan energi angin tersebut digunakan kincir angin yang saat ini banyak digunakan untuk membangkitkan tenaga listrik. Prinsip dasar kerja dari kincir angin untuk pembangkitan listrik adalah mengubah energi mekanik dari angin menjadi energi putar pada kincir, lalu putaran kincir digunakan untuk memutar generator yang akan menghasilkan listrik. Salah satu jenis kincir angin adalah kincir angin sumbu vertikal memiliki poros atau sumbu rotor utama yang disusun tegak lurus [1] seperti yang terlihat pada gambar 1. Kincir angin sumbu vertikal mampu memanfaatkan angin dari berbagai arah serta memiliki kemampuan self-starting yang bagus, sehingga hanya membutuhkan angin dengan kecepatan rendah untuk dapat memutar rotor dari turbin angin ini. Selain itu, torsi yang dihasilkan kincir angin jenis sumbu vertikal relatif tinggi. Peningkatan koefisien daya tergantung pada desain dari kincir angin Savonius yang dimodifikasi [3].

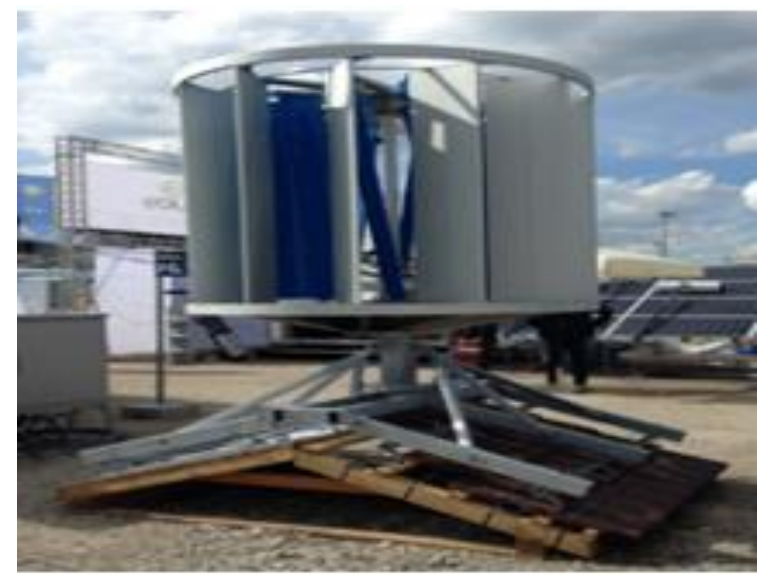

Gambar 1. Kincir angin sumbu vertikal secara sederhana

Salah satu upaya untuk meningkatkan kinerja kincir khususnya di putaran, maka diperlukan modifikasi atau pengembangan berupa pemasangan sudu pengarah [4]. Dengan pemasangan sudu pengarah diharapkan dapat mengurangi torsi negatif yang dihasilkan dan mengarahkan angin ke sudu cekung kincir. Berdasarkan latar belakang maka penulis merumuskan masalah yaitu bagaimana mengetahui karakteristik putaran kincir angin sumbu vertikal kelengkungan $90^{\circ}$ dengan dengan adanya penembahan sudu pengara.

\section{METODE PENELITIAN}

Langkah pertama yang dilakukan pada penelitian ini adalah melakukan perancangan dan pembuatan kincir angin sumbu vertikal tipe sudu $90^{\circ}$ dengan sudu pengarah, terlihat pada gambar 3 . Jenis penelitian yang digunakan adalah penelitian eksperimen, yaitu dengan melakukan pengamatan atau pengukuran terhadap variabel yang ditentukan untuk mengetahui kemampuan kerja kincir angin sumbu vertikal tipe sudu $90^{\circ}$ dengan memasang sudu pengarah. Kincir angin sumbu vertikal tipe sudu $90^{\circ}$ merupakan pengembangan dari kincir angin savonius konvensional yang berdasarkan hasil penelitian terdahulu memiliki koefisien power 0,4. Pengembangan dilakukan dengan menambahkan sudu pengarah, terlihat pada gambar 4 . Bentuk sudu, kincir angin sumbu vertikal tipe sudu $90^{\circ}$ di rancang dengan aspek rasio $(\mathrm{h} / \mathrm{R})=2,8$ dan overlep yaitu e/D $=0,2$, terlihat pada gambar 2 . Pengujian yang dilakukan secara eksperimen, yaitu dengan melakukan pengamatan atau pengukuran terhadap variabel yang ditentukan untuk mengetahui karakteristik putaran kincir angin sumbu vertikal tipe sudu $90^{\circ}$ dengan sudu pengarah. Pengamatan dilakukan pada kecepatan angin yang berbeda dengan variasi 
108 Peri Pitriadi, Asnawir. Pengaruh Penambahan Sudu Pengarah Pada Kincir Angin Sumbu Vertikal Kelengkungan $90^{\circ}$

posisi sudu pengarah seperti pada gambar 4 . Variasi yang dimaksud adalah posisi pembukaan dari $0^{\circ}$ sampai $50^{\circ}$ pada kecepatan angin $3,2 \mathrm{~m} / \mathrm{s}$ sampai $4,2 \mathrm{~m} / \mathrm{s}$.
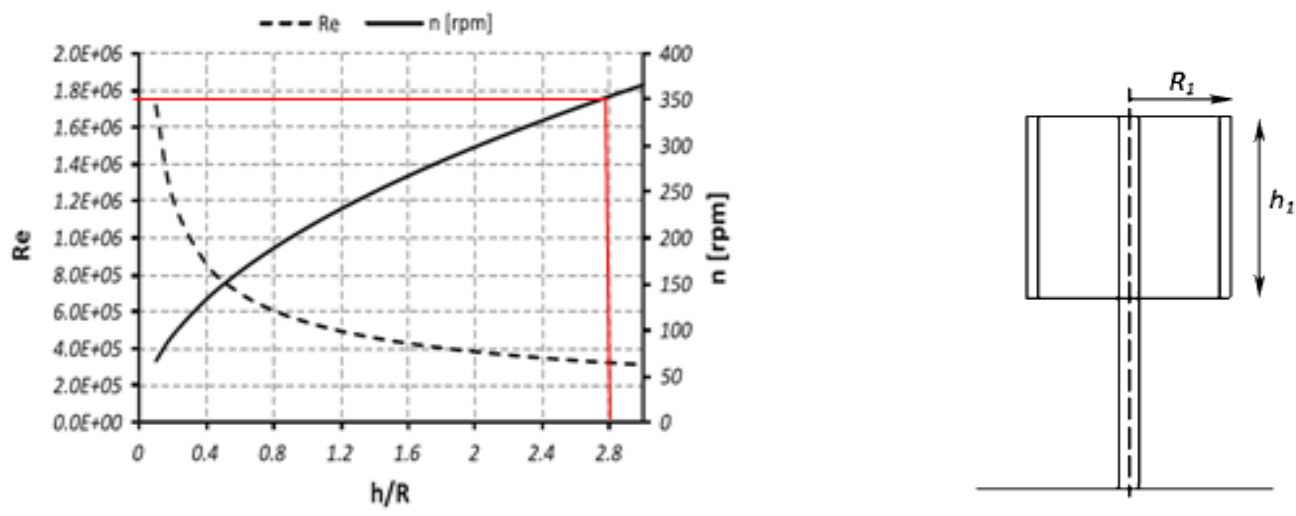

Gambar 2. Pengaruh aspek rasio $(\mathrm{h} / \mathrm{R})=2,8$ pada kinerja VAWT

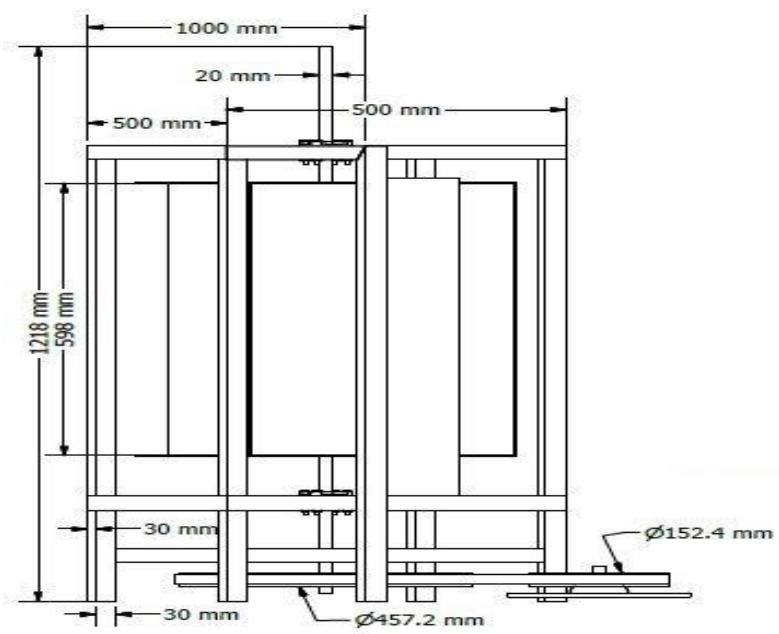

Gambar 3. Dimensi Model kincir angin sumbu vertikal tipe sudu $90^{\circ}$ dengan 3 sudu
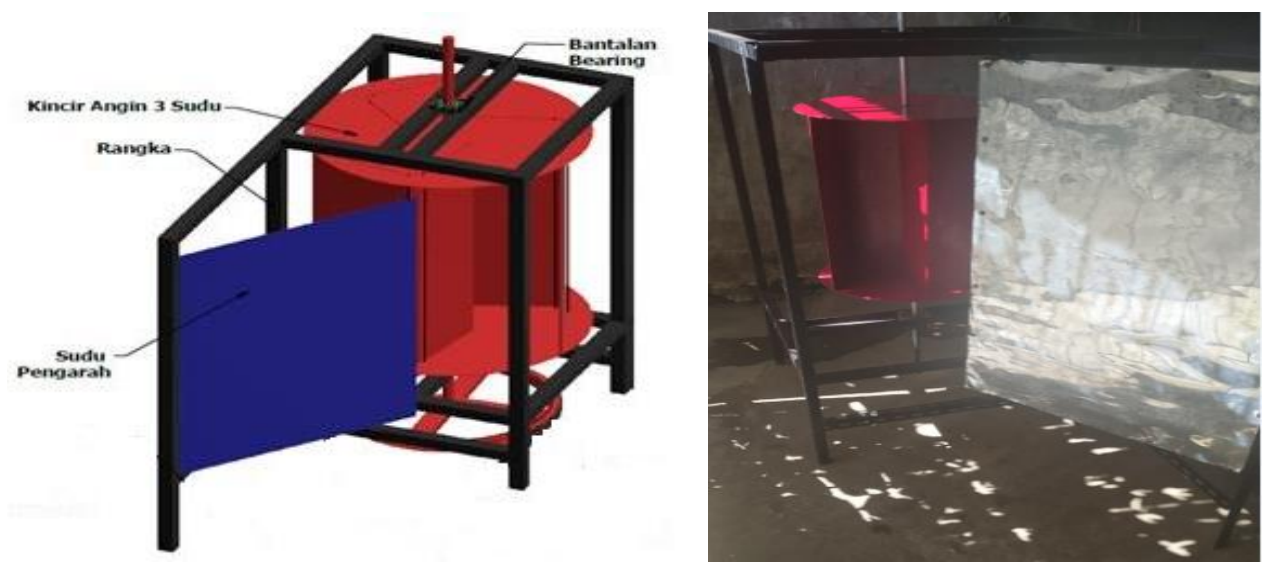

Gambar 4. Komponen Kincir Angin Sumbu Vertikal Kelengkungan Sudu 90 


\section{HASIL DAN PEMBAHASAN}

Tabel 1. Data pengujian pada kecepatan angin 3,2 m/s

\begin{tabular}{|c|c|c|c|}
\hline No & $\begin{array}{c}\text { Kecepatan Angin } \\
(\mathrm{m} / \mathrm{s})\end{array}$ & $\begin{array}{c}\text { Posisi Sudu Pengarah } \\
\left({ }^{\circ}\right)\end{array}$ & $\begin{array}{c}\text { Putaran Poros Kincir } \\
\text { Angin }(\mathrm{rpm})\end{array}$ \\
\hline 1 & 3,2 & $0^{\circ}$ & 37.2 \\
\hline 2 & 3,2 & $10^{\circ}$ & 41.3 \\
\hline 3 & 3,2 & $20^{\circ}$ & 50.1 \\
\hline 4 & 3,2 & $30^{\circ}$ & 53.0 \\
\hline 5 & 3,2 & $40^{\circ}$ & 58.2 \\
\hline 6 & 3,2 & $50^{\circ}$ & 63.3 \\
\hline
\end{tabular}

Tabel 2. Data pengujian pada kecepatan angin 3,6 m/s

\begin{tabular}{|c|c|c|c|}
\hline No & $\begin{array}{c}\text { Kecepatan Angin } \\
(\mathrm{m} / \mathrm{s})\end{array}$ & $\begin{array}{c}\text { Posisi Sudu Pengarah } \\
\left({ }^{\circ}\right)\end{array}$ & $\begin{array}{c}\text { Putaran Poros Kincir } \\
\text { Angin }(\mathrm{rpm})\end{array}$ \\
\hline 1 & 3,6 & $0^{\circ}$ & 40.1 \\
\hline 2 & 3,6 & $10^{\circ}$ & 44.3 \\
\hline 3 & 3,6 & $20^{\circ}$ & 53.4 \\
\hline 4 & 3,6 & $30^{\circ}$ & 62.4 \\
\hline 5 & 3,6 & $40^{\circ}$ & 65.2 \\
\hline 6 & 3,6 & $50^{\circ}$ & 80.6 \\
\hline
\end{tabular}

Tabel 3. Data pengujian pada kecepatan angin $4,0 \mathrm{~m} / \mathrm{s}$

\begin{tabular}{|c|c|c|c|}
\hline No & $\begin{array}{c}\text { Kecepatan Angin } \\
(\mathrm{m} / \mathrm{s})\end{array}$ & $\begin{array}{c}\text { Posisi Sudu Pengarah } \\
\left({ }^{\circ}\right)\end{array}$ & $\begin{array}{c}\text { Putaran Poros Kincir Angin } \\
(\mathrm{rpm})\end{array}$ \\
\hline 1 & 4.0 & $0^{\circ}$ & 52.6 \\
\hline 2 & 4.0 & $10^{\circ}$ & 60.3 \\
\hline 3 & 4.0 & $20^{\circ}$ & 64.9 \\
\hline 4 & 4.0 & $30^{\circ}$ & 70.6 \\
\hline 5 & 4.0 & $40^{\circ}$ & 77.2 \\
\hline 6 & 4.0 & $50^{\circ}$ & 82.3 \\
\hline
\end{tabular}

Tabel 4. Data pengujian pada kecepatan angin $4,2 \mathrm{~m} / \mathrm{s}$

\begin{tabular}{|c|c|c|c|}
\hline No & $\begin{array}{c}\text { Kecepatan Angin } \\
(\mathrm{m} / \mathrm{s})\end{array}$ & $\begin{array}{c}\text { Posisi Sudu Pengarah } \\
\left({ }^{\circ}\right)\end{array}$ & $\begin{array}{c}\text { Putaran Poros Kincir Angin } \\
(\mathrm{rpm})\end{array}$ \\
\hline 1 & 4.2 & $0^{\circ}$ & 57.7 \\
\hline 2 & 4.2 & $10^{\circ}$ & 69.9 \\
\hline 3 & 4.2 & $20^{\circ}$ & 72.0 \\
\hline 4 & 4.2 & $30^{\circ}$ & 77.4 \\
\hline 5 & 4.2 & $40^{\circ}$ & 86.5 \\
\hline 6 & 4.2 & $50^{\circ}$ & 96.2 \\
\hline
\end{tabular}




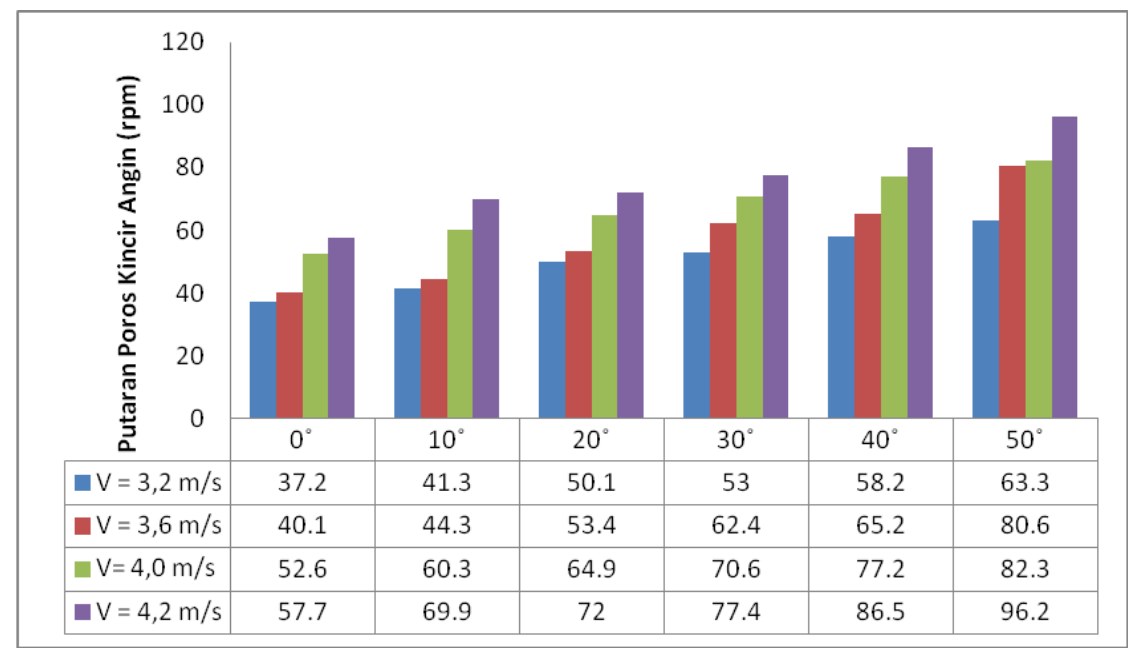

Gambar 5. Hubungan antara Kecepatan Angin dengan putaran poros Kincir Angin

Untuk pembukaan sudu $0^{\circ}$ atau kincir tanpa sudu pengarah dengan kecepatan angin $4,2 \mathrm{~m} / \mathrm{s}$ diperoleh nilai putaran kincir 57,7 rpm dan pada pembukaan sudu pengarah $50^{\circ}$ diperoleh putaran kincir 96,2 rpm. Dari data tersebut dapat di simpulkan bahwa pada kecepatan angin yang sama dengan pembukaan sudu pengarah yang berbeda, memberikan pengaruh besarnya putaran yang di hasilkan kincir. Artinya semakin besarnya pembukaan sudu pengarah, maka putaran kincir akan semakin besar pada kecepatan angin konstan atau sama.

Berdasarkan data hasil penelitian untuk kecepatan angin yang berbeda, diperoleh bahwa pada kecepatan angin $4,2 \mathrm{~m} / \mathrm{s}$ pada pembukaan sudu pengarah $50^{\circ}$ nilai putaran poros tertinggi $96,2 \mathrm{rpm}$ dan untuk kecepatan angin terendah $3,2 \mathrm{~m} / \mathrm{s}$ pada pembukaan sudu pengarah $50^{\circ}$ diperoleh nilai putaran poros kincir terendah 63,3 rpm. Maka dapat di simpulkan bahwa pemasangan sudu pengarah pada kincir mampu meningkatkan putaran kincir angin seiring dengan kenaikan kecepatan angin yang menumbuk sudu kincir angin. Secara keseluruhan kinerja kincir angin setelah dipasangi sudu pengarah dapat di lihat pada gambar 5 .

\section{KESIMPULAN}

1. Pengaruh dari sudu pengarah yang dipasang adalah semakin besar pembukaan sudu yang diberikan maka putaran poros kincir juga akan semakin besar. Semakin besar kecepatan angin yang diberikan putaran kincir yang dihasilkan juga akan semakin besar dimana Kecepatan angin 4,2 m/s dengan pembukaan sudu Sudu $0^{\circ}$, putaran kincir 57,7 rpm dan pembukaan Sudu $50^{\circ}$, putaran kincir $96,2 \mathrm{rpm}$.

2. Semakin besar kecepatan angin yang diberikan putaran kincir yang dihasilkan juga akan semakin besar

\section{DAFTAR PUSTAKA}

[1] Bahri S, Unjuk kerja turbin angin savonius dua tingkat empat sudu lengkung L, Jurnal Seminar Tahunan Teknik Mesin, 2014, pp 978-602.

[2] Fitranda R. \& Siregar, Karakteristik turbin angin savonius 2 dan 3 blade dengan menggunakan bantuan guide vane, Jurnal Teknik Mesin, 2014, pp 125-131.

[3] Marnoto, Peningkatan efisiensi kincir angin poros vertikal melalui sistem melalui buka tutup sirip 
3 sudu, Jurnal Teknik Mesin, 2011, pp122-129.

[4] Pradana A, Rancang bangun turbin angin vertikal jenis savonius dengan variasi profil kurva blade untuk memperoleh daya maksimum, Jurnal Teknik POMITS, 2013, pp 1-6.

[5] Sarjono B., Pengaruh perubahan jumlah blade spiral $5 \& 3$ terhadap performa kincir angin savonius dengan bentuk blade spiral, Majalah Ilmiah STTR Cepu, 2011,pp1693 - 7066.

[6] Sumiati, Pengujian turbin angin savonius tipe u tiga sudu di lokasi pantai air tawar padang, Jurnal Teknik Mesin, 2012, pp1829-8958 